\title{
A European perspective on the market accessibility of biosimilars
}

This article was published in the following Dove Press journal:

Biosimilars

15 November 2012

Number of times this article has been viewed

\author{
Paul J Declerck' \\ Steven Simoens ${ }^{2}$ \\ 'Laboratory for Pharmaceutical \\ Biology, ${ }^{2}$ Research Centre \\ for Pharmaceutical Care and \\ Pharmacoeconomics, Department \\ of Pharmaceutical and \\ Pharmacological Sciences, KU \\ Leuven, Leuven, Belgium
}

\begin{abstract}
Biopharmaceuticals are complex molecules produced by living cells. Copies of these drugs, called biosimilars, are not identical to their reference medicine, and therefore specific regulatory requirements for registration apply. Pharmaceutical quality evaluation requires a complete dossier and a detailed comparative analysis to the reference drug. However, nonclinical and clinical requirements are much less extensive compared to the requirements for an innovator. Therefore, at the time of introduction onto the market, only limited clinical experience is available for the biosimilar. Differences of $15 \%-30 \%$ between the acquisition price of biosimilars and their corresponding reference biopharmaceuticals have been suggested in the literature. Although the percentage price difference between reference biopharmaceuticals and biosimilar medicines may be limited, absolute savings are still likely to be substantial when calculated with respect to expensive reference biopharmaceutical medicines. Although an economic evaluation needs to be carried out in an increasing number of European countries to inform reimbursement decisions, uncertainty exists about how such an economic evaluation should be conducted for a biosimilar. The assessment of the cost-effectiveness of a biosimilar for reimbursement purposes depends primarily on the relative efficacy, given that a biosimilar is likely to be less expensive than the reference biopharmaceutical. To date, the question of meaningful differences in efficacy between biosimilar and biopharmaceutical drugs has not been answered. Due to a lack of demand-side incentives, biosimilar medicines have enjoyed limited success in Europe to date. Other factors that inhibit the market accessibility of biosimilars include the limited number of companies that have the expertise and the financial ability to manufacture, gain marketing authorization for, and commercialize biosimilars; physician brand loyalty to reference biopharmaceutical medicines; application of rebate contracts to reference biopharmaceutical medicines following expiry of protection; and life-cycle management strategies of companies marketing reference biopharmaceutical medicines.
\end{abstract}

Keywords: biopharmaceutical, biological medicine, registration, pricing, reimbursement

\section{Introduction}

Biopharmaceuticals, also called "biological medicinal products" or "biological medicines," are drugs whose active drug substance is made by or derived from a living organism by means of recombinant DNA and/or controlled gene-expression methods. These products are polypeptides, (glyco)proteins, complex polysaccharides, and/or nucleic acids that have much more complex molecular characteristics than smallmolecule drugs.

The composition of the marketed biopharmaceutical product is influenced by many variables, such as the type of expression system (eg, bacteria, yeast, mammalian cells), the growth conditions, the purification process, the actual formulation, 
and the conditions during storage and transport. Thus, for biopharmaceuticals, "the process defines the product." During cellular synthesis, these structures are often modified by post-translational modifications such as glycosylation phosphorylation, sulfation, methylation, acetylation, and hydroxylation, which may affect biological activity and which results in an intrinsic molecular heterogeneity. This heterogeneity is further increased by varying degrees of peptide denaturation, aggregation, oxidation, and degradation. Since this structural variability is substantial and can be very subtle, the currently available analytical techniques are insufficient to fully characterize them. In contrast, lowmolecular weight, small-molecule drugs are produced by well-controlled and highly reproducible chemical reactions; they are molecules with a small, well-defined and stable chemical structure, and can be completely characterized by analytical methods. ${ }^{1,2}$

Importantly, and in contrast to small-molecule drugs, biopharmaceuticals are potentially immunogenic. In this respect, subtle structural differences (eg, consequent to small differences in the number and type of product variants) may significantly affect the immunogenic potential of the drug product. ${ }^{3,4}$ For instance, a study demonstrated that recombinant human insulin was less immunogenic than porcine insulin, but still led to the development of antibodies in $44 \%$ of diabetic patients. ${ }^{5}$ On the other hand, product- or processrelated impurities can also provoke an immune response. ${ }^{1,6}$

When all intellectual property protection, data, and marketing exclusivity for the reference biopharmaceutical have expired, "copying" and marketing of these biological substances can be offered by any other biotech company. To date, biosimilars of recombinant human erythropoietins (epoetin alfa and epoetin zeta), granulocyte colony-stimulating factors (filgrastim), and human growth hormones (somatropin) have entered the European market (see Table 1). Even though protection placed on biopharmaceutical low-molecular weight heparins and recombinant human insulins expired a few years ago, no biosimilar versions are available yet. Currently (July 2012), three applications for biosimilar versions of human insulin and one application for a biosimilar version of follitropin alfa are under evaluation by the European Medicines Agency (EMA). Also, the first application for a biosimilar version of a monoclonal antibody, ie, infliximab, is under evaluation by the EMA. Consequent to the proximate patent expiry of other monoclonal antibody-based biopharmaceuticals (eg, rituximab, trastuzumab, adalimumab), more biosimilar versions of monoclonal antibodies are to be expected in the near future.
The European Union (EU) has paved the way in establishing a regulatory framework for the marketing authorization of biosimilars, based on comparative quality and clinical pharmacokinetic studies, nonclinical studies, clinical pharmacodynamic studies, and limited toxicology studies, as well as comparative clinical efficacy and tolerability studies. In the USA, a regulatory framework was established in $2010,{ }^{7}$ but no biosimilar product has been approved under this framework to date.

The market accessibility of biosimilars may reduce costs to patients and social security systems. In general, the literature expects biosimilar medicines to be around $15 \%$ to $30 \%$ cheaper than reference biopharmaceutical medicines. ${ }^{8,9}$ For instance, a European analysis observed that in 2009, the percentage price difference between reference biopharmaceuticals and biosimilar medicines amounted to $14 \%$ for somatropin, $17 \%$ for erythropoietin, and $35 \%$ for filgrastim. ${ }^{10}$ The market accessibility of biosimilars is also motivated by key government objectives related to, for instance, building manufacturing capabilities within a country. In this respect, some European countries have implemented industrial policies to encourage the development of biological products. ${ }^{11}$

The aim of this article is to introduce and describe specific issues related to the market accessibility of biosimilars in the EU by focusing on their registration, pricing, reimbursement, prescribing, and dispensing.

\section{Registration}

Biopharmaceuticals are made by living cells. Because of their intrinsic complexity and because no two cell lines, developed independently, can be considered identical, biopharmaceuticals cannot be fully copied. This is recognized by the European regulatory authorities and has resulted in the establishment of the term "biosimilar" in recognition of the fact that, while biosimilar products are similar to the original product, they are not exactly the same. ${ }^{12,13}$ European legislation has included specific guidelines for the approval of biosimilars since 2005 .

The requirements for approval of generics are generally considered by European regulatory authorities to be inadequate for establishing the quality, efficacy, and safety of biosimilars. For instance, for a generic, low-molecular weight, small-molecule drug, it is sufficient to demonstrate comparable quality and a comparable clinical pharmacokinetic profile - ie, bioequivalence - with a reference (innovator) product, to obtain regulatory approval. ${ }^{14}$ Because biosimilars are similar but not identical to the original product, the EMA not only requires comparative quality and clinical 
Table I Approved biosimilars in Europe as of July 2012

\begin{tabular}{|c|c|c|c|c|c|}
\hline $\begin{array}{l}\text { International } \\
\text { nonproprietary } \\
\text { name }\end{array}$ & Indication & $\begin{array}{l}\text { Reference } \\
\text { product }\end{array}$ & Biosimilar & $\begin{array}{l}\text { Price } \\
\text { (in Belgium) }\end{array}$ & $\begin{array}{l}\text { Year } \\
\text { of approval }\end{array}$ \\
\hline \multirow[t]{2}{*}{ Somatropin } & Treatment of growth hormone & Genotropin ${ }^{\circledR}$ & & $€ 28.7$ per mg & 1987 \\
\hline & deficiency & & Omnitrope ${ }^{\circledR}$ & $€ 22.4$ per mg & 2006 \\
\hline \multirow[t]{2}{*}{ Somatropin } & Treatment of growth hormone & Humatrope ${ }^{\circledR}$ & & $€ 23.7$ per mg & 1990 \\
\hline & deficiency & & Valtropin ${ }^{\circledR}$ & - & 2006 \\
\hline \multirow[t]{4}{*}{ Epoetin alfa } & $\begin{array}{l}\text { Treatment of anemia and reduction } \\
\text { of transfusion requirements }\end{array}$ & Eprex $^{\circledR}$ & & $\begin{array}{l}€ I 0 \mid \\
(I 0,000 \mathrm{IE} / \mathrm{I} \mathrm{mL})\end{array}$ & 1990 \\
\hline & & & Binocrit $^{\circledast}$ & $\begin{array}{l}€ 42.49 \\
(1000 \mathrm{IE} / 0.5 \mathrm{~mL})\end{array}$ & 2007 \\
\hline & & & Epoetin alfa Hexal ${ }^{\circledR}$ & - & 2007 \\
\hline & & & Abseamed $^{\circledR}$ & - & 2007 \\
\hline \multirow[t]{3}{*}{ Epoetin zeta } & $\begin{array}{l}\text { Treatment of anemia and reduction } \\
\text { of transfusion requirements }\end{array}$ & Eprex $^{\circledast}$ & & $\begin{array}{l}€ I 0 \mid \\
(I 0,000 \mathrm{IE} / \mathrm{I} \mathrm{mL})\end{array}$ & 1990 \\
\hline & & & Silapo ${ }^{\circledR}$ & - & 2007 \\
\hline & & & Retacrit $^{\circledast}$ & $\begin{array}{l}€ 42.49 \\
(1000 \mathrm{IE} / 0.5 \mathrm{~mL})\end{array}$ & 2007 \\
\hline \multirow[t]{8}{*}{ Filgrastim } & Prevention or reduction of neutropenia & Neupogen ${ }^{\circledR}$ & & $€ 279.3$ per mg & 1991 \\
\hline & & & Biograstim $^{\circledast}$ & - & 2008 \\
\hline & & & Filgrastim Ratiopharm ${ }^{\circledast}$ & - & 2008 \\
\hline & & & Ratiograstim $^{\circledR}$ & - & 2008 \\
\hline & & & Tevagrastim $^{\circledR}$ & $€ 223.4 / \mathrm{mg}$ & 2008 \\
\hline & & & Zarzio $^{\circledR}$ & $€ 223.4 / \mathrm{mg}$ & 2009 \\
\hline & & & Filgrastim Hexal $^{\circledR}$ & - & 2009 \\
\hline & & & Nivestim ${ }^{\circledast}$ & - & 2010 \\
\hline
\end{tabular}

pharmacokinetic studies, but also nonclinical studies, clinical pharmacodynamic studies, and limited toxicology studies, as well as comparative clinical efficacy and tolerability studies. ${ }^{13,15,16}$ However, nonclinical pharmacokinetics, safety pharmacology, reproduction toxicology, mutagenicity, and carcinogenicity studies are not mandatory for approval of a biosimilar, in contrast to the reference biopharmaceutical.

The guideline for quality requirements by the Committee for Medicinal Products for Human use (CHMP) ${ }^{16}$ states that the active substance in a biosimilar should be similar to the one in the reference product. Demonstration of similarity requires tests for the biosimilar's comparability to the chosen reference product. This implies the use of appropriately selected state-of-the-art analytical methods and includes the comparative evaluation of physicochemical parameters, biological activity using relevant bioassays, and a qualitative and quantitative comparative assessment of purity and impurity profiles. The guideline also indicates that "it is not expected that the quality attributes in the similar biological and reference medicinal products will be identical." ${ }^{16}$ However, the CHMP requires that any difference in the quality attributes between the biosimilar and its reference product should be justified in relation to its potential impact on efficacy and tolerability. The existence of differences in quality attributes between a biosimilar and the reference product is reported in the European public assessment reports made available upon approval of the biosimilar. ${ }^{17}$ On the other hand, the use of a distinct international nonproprietary name (eg, epoetin zeta as the active drug substance in a biosimilar with a reference biological product containing epoetin alfa as the active drug substance) also implies differences between the biosimilar and the reference product.

The general nonclinical and clinical requirements for a biosimilar were published by the CHMP in $2006 .{ }^{15}$ These are much fewer compared to the requirements for an innovator, implying that less de novo evidence is required of biosimilars than of innovators. The principle is based mainly upon data obtained by comparative studies (biosimilar versus reference). In addition to the general nonclinical and clinical guidelines, product class-specific annexes to these guidelines have also been adopted for biosimilars containing as their active substances recombinant interferon alpha, recombinant 
granulocyte-colony stimulating factor, recombinant somatropin, recombinant insulin, low-molecular-weight heparins, and/or recombinant erythropoeitins. A draft guideline for biosimilars containing monoclonal antibodies, as well as concept papers, for biosimilars containing recombinant interferon beta and recombinant follicle-stimulation hormone have been released for consultation.

According to CHMP guidelines, nonclinical comparative tests should in general comprise in vitro studies (eg, receptor-binding studies or cell-based assays), as well as in vivo pharmacodynamic studies. In addition, given the immunogenic potential of biopharmaceuticals, at least one repeat-dose toxicity study should be performed, including toxicokinetic measurements such as determination of antibody titers, cross-reactivity, and neutralizing capacity.

CHMP guidelines also state that clinical studies for regulatory approval of a biosimilar should include comparative pharmacokinetic and pharmacodynamic studies in healthy volunteers, followed by comparative efficacy and tolerability trials. The guideline states specifically "The clinical comparability exercise is a stepwise procedure that should begin with pharmacokinetic (PK) and pharmacodynamic (PD) studies followed by clinical efficacy and safety trial(s) or, in certain cases, pharmacokinetic/pharmacodynamic (PK/PD) studies for demonstrating clinical comparability." The latter studies are usually only performed in the most sensitive and most relevant target patient population(s). In certain cases, therapeutic similarity demonstrated in one indication may be extrapolated to other indications of the reference medicinal product. However, extrapolation remains a matter of debate, especially when different indications imply the use of significantly different doses ${ }^{18}$ or where extrapolation to use in healthy individuals is concerned (eg, use of filgrastim for stem-cell mobilization and collection in healthy donors).

On the other hand, the CHMP puts special emphasis on assessment of the clinical tolerability of a biosimilar, because of its potential immunogenicity. CHMP guidelines also state that the risk of immunogenicity may differ depending on the patient's underlying disease, on the stage of the disease, and on the therapeutic indication of the product. For instance, the probability of an immune response may be higher for chronic infections (since the immune system of the patient is in an activated state) than for conditions where the immune system is impaired (eg, advanced metastatic disease, organ failure). ${ }^{19}$ Since immunogenicity is a long-term event, gathering of immunogenicity data after marketing authorization remains an important prerequisite.

\section{Pricing}

There are a number of reasons why price differences between reference biopharmaceuticals and biosimilar medicines are likely to be smaller than those observed between the originator and generic small-molecule medicines:

- The development time for a biosimilar medicine is 5 to 8 years (consisting of 1-2 years for cell biology, 1 year for process analysis, 2-4 years for clinical studies, and 1 year for market approval) as compared to 3 years for a generic medicine. ${ }^{20}$

- The research and development process needs to generate clinical trial data in order to gain marketing authorization. For instance, a US study has estimated that the costs of biosimilar trials amount to US\$10-\$40 million. ${ }^{21}$

- The need to set up manufacturing processes involves substantial expense and time: the required investment in manufacturing processes is expected to range from US\$250 to US\$450 million. ${ }^{21}$

- There is the requirement in Europe to institute expensive post-marketing pharmacovigilance programs that follow up on the long-term safety and effectiveness of a biosimilar medicine.

- Pricing regulations that typically apply to generic medicines, such as mandatory price discounts, referencepricing systems, and tenders, may also be imposed by European countries on biosimilar medicines. For instance, France has enforced price discounts on biosimilar erythropoietins and biosimilar human growth hormones. Germany has included biosimilar erythropoietins and biosimilar human growth hormones in their reference-pricing system. ${ }^{22}$ Hospital purchases of biosimilar erythropoietins and biosimilar granulocyte colony-stimulating factors in the UK tend to be made by means of tendering, in which safety, efficacy, availability, cost-effectiveness, and price are the most important purchasing criteria. ${ }^{23}$

This cost picture not only increases prices of biosimilar medicines, but also is expected to limit the number of biosimilar companies that enter the market and thus reduce price competition in the off-patent biopharmaceutical market. ${ }^{24}$

The price difference between reference biopharmaceuticals and biosimilar medicines may also depend on their respective market shares: more substantial price differences have been documented in countries where biosimilars attained a higher market share. For instance, in Germany, biosimilar erythropoietins had a market share by volume of approximately 14\%-30\% after 2 years on the market, and were priced at around $75 \%$ of the price of the reference biopharmaceutical medicine. ${ }^{25}$ 
In India, non-innovator ${ }^{\mathrm{a}}$ erythropoietins had a market share by volume of $40 \%$ and a price of $45 \%-75 \%$ of the price of the reference biopharmaceutical medicine. ${ }^{26}$

Although the percentage price difference between reference biopharmaceuticals and biosimilar medicines may be limited, absolute savings are still likely to be substantial when calculated with respect to expensive reference biopharmaceutical medicines. For instance, if the top seven reference biopharmaceutical medicines were replaced by biosimilars that were $20 \%$ cheaper, the EU would save more than $€ 2$ billion per year. ${ }^{27}$ Furthermore, thanks to the lower price of biosimilar filgrastim in the UK, many physicians moved filgrastim back to first-line treatment, thereby preventing hospital readmissions due to infection and enhancing access to health care.

\section{Reimbursement}

While registration of biosimilars is governed by the EMA regulatory framework, reimbursement is the national responsibility of each member state. An increasing number of European countries rely on the instrument of economic evaluation to inform their pharmaceutical reimbursement decisions. An economic evaluation is a comparative analysis of a health technology (eg, a biosimilar medicine) and a relevant comparator (usually the current standard of care) in terms of both their costs and health outcomes. ${ }^{28}$ The appropriate comparator of a biosimilar tends to be the reference biopharmaceutical medicine. However, when a biosimilar is developed of an older reference biopharmaceutical medicine (eg, the filgrastim biosimilar of Neupogen ${ }^{\circledR}$, for preventing febrile neutropenia) for which a second-generation reference biopharmaceutical medicine has become the current standard of care (eg, Neulasta $\left.{ }^{\circledR}\right)$, then it follows that the economic evaluation needs to compare the filgrastim biosimilar with the second-generation reference biopharmaceutical medicine. ${ }^{29}$

The specific technique of economic evaluation to be applied depends on the interchangeability of the reference biopharmaceuticals and the biosimilar medicines. ${ }^{30}$ Interchangeability needs to be established by appropriate comparative trials between the biosimilar and the reference biopharmaceutical medicine for a specific indication. Studies adequately designed to evaluate full interchangeability are currently lacking. In addition, the EMA may allow the extrapolation of data to another indication of the reference

asince no stringent guidelines exist in India, similarity is not always demonstrated, and therefore the term "biosimilar" is not justified. biopharmaceutical medicine, without a clinical evaluation of the biosimilar in this particular patient population.

If head-to-head trials point to equal efficacy of the biosimilar and reference biopharmaceutical medicine, the economic evaluation can take the form of a cost-minimization analysis, and the least expensive medicine needs to be recommended. ${ }^{31}$ In this case, replacement of the reference biopharmaceutical medicine with the biosimilar will maintain health outcomes at reduced costs. ${ }^{32}$ Reimbursement applications based on costminimization analyses have been considered in European countries for biosimilars of epoetin alfa, filgrastim, and somatropin. ${ }^{33-35}$

If the biosimilar has a different efficacy than the reference biopharmaceutical medicine, a full economic evaluation needs to be conducted by means of a cost-effectiveness analysis, a cost-utility analysis, or a cost-benefit analysis. ${ }^{31}$ In this case, the savings arising from less-expensive biosimilars need to be weighed against the impact on total costs and health outcomes. ${ }^{32}$ For instance, if a biosimilar has lower efficacy than the reference biopharmaceutical medicine, therapy with the biosimilar may give rise to additional health-care costs (eg, additional physician consultations or hospitalization) and increased costs of productivity loss. Some reimbursement applications for biosimilars in European countries have considered two scenarios: in the first scenario, the biosimilar and the reference biopharmaceutical medicine have equal efficacy, and a cost-minimization analysis is carried out; in the second scenario, a full economic evaluation is conducted taking into account meaningful differences in efficacy between the biosimilar and the reference biopharmaceutical medicine. ${ }^{36}$ Furthermore, such exercises have conducted sensitivity analyses, examining the impact of changes in relative efficacy on the cost-effectiveness of the biosimilar.

\section{Prescribing and dispensing}

Today, few European countries have implemented specific demand-side policies to prescribe or dispense biosimilar medicines. For instance, Belgium attempts to encourage the uptake of biosimilar medicines by including them in physicians' quotas for prescribing cheap medicines and by incorporating erythropoietins in the hospital lump sum financing system for medicines. In June 2011 in Germany, biosimilar erythropoietins attained a share of the erythropoietin market $-25 \%$ by volume - resulting from the regional imposition of biosimilar erythropoietin quotas ranging from $10 \%$ to $40 \%$ and from physician loyalty to national biosimilar companies. In addition, health-insurance funds did not 
encourage the inclusion of reference erythropoietins in rebate contracts, following patent expiry. ${ }^{37}$

One demand-side policy relates to the substitution of a biosimilar for a reference biopharmaceutical medicine, ${ }^{30}$ which is a national responsibility of European countries. In practice, substitution by a pharmacist of a biosimilar for a reference biopharmaceutical medicine is not allowed in any European country ${ }^{27}$ and is not recommended by the World Health Organization or by medical societies. ${ }^{38-40}$ The EMA also advises that the physician should be in charge of the decision to switch between the reference and biosimilar, or vice versa. ${ }^{41}$ In contrast, the US Food and Drug Administration can allow substitution of a biosimilar for a reference biopharmaceutical medicine without approval of the prescribing physician, but only on the condition that interchangeability has been proven. ${ }^{24}$

Even if a European country were to allow substitution of a biosimilar for a reference biopharmaceutical medicine, it remains to be seen whether physicians who have gained long-term experience with prescribing reference biopharmaceutical medicines would be willing to switch existing patients to a biosimilar medicine. ${ }^{25}$ In this respect, it should be noted that biosimilar medicines have gained a foothold in some European countries as the result of a strategy to persuade physicians to start new patients on a biosimilar rather than to switch existing patients. For instance, the market accessibility of the biosimilar filgrastim has been facilitated by its acute use in new patients, rather than having to rely on switching existing patients. In Hungary, new patients need to be treated with biopharmaceutical medicines that can be, at most, 5\% more expensive than the cheapest available product. However, existing patients have the right to continue receiving the reference biopharmaceutical medicine. ${ }^{10}$

Given that specific demand-side policies to promote the use of biosimilars are largely absent in European countries, biosimilar companies are likely to have to invest substantial resources in developing commercial strategies to create demand for biosimilars. ${ }^{30}$ This may be achieved by means of direct negotiations with those who fund or pay for health care or by detailing biosimilars directly to physicians. ${ }^{42}$

\section{Market access}

The market accessibility of biosimilar medicines is facilitated by the increased utilization and expanding indications of reference biopharmaceutical medicines; the current and imminent expiry of protection on major classes of biopharmaceutical medicines (eg, monoclonal antibodies); and the cost-containment measures introduced by many European countries in response to the current financial and economic crisis. However, in general, biosimilar medicines have enjoyed limited success in the EU to date. The market accessibility of biosimilars is inhibited by many factors: (1) the difficulties and expenses involved in manufacturing biosimilars; (2) the high cost of fulfilling regulatory requirements to obtain marketing authorization; (3) the limited number of companies that are able to manufacture and commercialize biosimilars; (4) the brand loyalty of physicians and patients to reference biopharmaceutical medicines; (5) the prohibition against substituting a biosimilar for a reference biopharmaceutical medicine; (6) the application of rebate contracts to reference biopharmaceutical medicines following expiry of protection; and (7) the life-cycle management strategies of companies that are marketing reference biopharmaceutical medicines (eg, developing second-generation reference biopharmaceutical medicines).

In light of the specific features of the market accessibility of biosimilar medicines discussed above, biosimilar markets in European countries are expected to be characterized by brand-to-brand competition between biosimilar and reference biopharmaceutical medicines rather than the brand-to-generic competition that is observed in some off-patent markets of small-molecule medicines. ${ }^{30}$ This is, for example, reflected in the advice of the EMA to prescribe biosimilar medicines by brand name, as is already the case in countries such as Austria, the Czech Republic, and Germany. ${ }^{25}$

\section{Conclusion}

Although this is not a currently consistent practice, the question of the degree of comparability between a biosimilar and the reference biopharmaceutical needs to be considered for market-access purposes in the EU. Even though the EMA has imposed regulatory requirements for the approval of biosimilars, it is our opinion that these requirements are inadequate for fully establishing the efficacy and safety of biosimilars. Furthermore, reimbursement authorities need to weigh savings arising from the lower price of a biosimilar against the impact of any differences between a biosimilar and its reference biopharmaceutical on the overall efficacy and total health-care costs of therapy. Regulatory, pricing, and reimbursement authorities should therefore seek more complete information, when carefully considering market access for biosimilars. Comparative studies need to be set up to collect the data necessary to follow up on and evaluate uncertainties surrounding the longer-term safety, effectiveness, and 
cost-effectiveness of a biosimilar, as compared to the current standard treatment.

\section{Disclosure}

This research received no specific grant from any funding agency in the public, commercial, or not-for-profit sectors. SS holds the EGA chair "European policy towards generic medicines." The authors have no conflicts of interest that are directly relevant to the content of this manuscript.

\section{References}

1. Crommelin D, Bermejo T, Bissig M, et al. Biosimilars, generic versions of the first generation of therapeutic proteins: do they exist? Contrib Nephrol. 2005;149:287-294.

2. Crommelin DJ, Storm G, Verrijk R, de LL, Jiskoot W, Hennink WE. Shifting paradigms: biopharmaceuticals versus low molecular weight drugs. Int J Pharm. 2003;266:3-16.

3. Kessler M, Goldsmith D, Schellekens H. Immunogenicity of biopharmaceuticals. Nephrol Dial Transplant. 2006;21 Suppl 5:v9-v12.

4. Sauerborn M, Brinks V, Jiskoot W, Schellekens H. Immunological mechanism underlying the immune response to recombinant human protein therapeutics. Trends Pharmacol Sci. 2010;31:53-59.

5. Fineberg SE, Kawabata TT, Finco-Kent D, Fountaine RJ, Finch GL, Krasner AS. Immunological responses to exogenous insulin. Endocr Rev. 2007;28:625-652.

6. Schellekens H, Casadevall N. Immunogenicity of recombinant human proteins: causes and consequences. J Neurol. 2004;251 Suppl 2: II4-II9.

7. United States Congress. Patient Protection and Affordable Care Act. One Hundred Eleventh Congress of the United States of America; January 5, 2010; Washington. Available from: http://www.gpo.gov/fdsys/ pkg/BILLS-111hr3590enr/pdf/BILLS-111hr3590enr.pdf. Accessed December 6, 2010.

8. Long M, Trout J, Akpinar P. Biosimilars: HGH to TNFS, how will payers respond? ISPOR 12th Annual European Congress; October 26, 2009; Paris.

9. Mellstedt H. The future of biosimilars. Hosp Pharm Europe. 2010;49:33-34.

10. Rovira J, Espin J, Garcia L, Olry de Labry A. The Impact of Biosimilars' Entry in the EU Market. European Commission; 2011. Available from: http://ec.europa.eu/enterprise/sectors/healthcare/files/docs/biosimilars_market_012011_en.pdf. Accessed April 28, 2012.

11. Danzon PM, Furukawa MF. Prices and availability of biopharmaceuticals: an international comparison. Health Aff (Millwood). 2006;25:1353-1362.

12. Declerck PJ. Biotherapeutics in the era of biosimilars: what really matters is patient safety. Drug Saf. 2007;30:1087-1092.

13. Committee for Medicinal Products for Human Use (CHMP). Guideline on Similar Biological Medicinal Products. London: European Medicines Agency; 2005. Available from: http://www.ema.europa. eu/docs/en_GB/document_library/Scientific_guideline/2009/09/ WC500003517.pdf. Accessed December 6, 2010.

14. Meredith PA. Potential concerns about generic substitution: bioequivalence versus therapeutic equivalence of different amlodipine salt forms. Curr Med Res Opin. 2009;25:2179-2189.

15. Committee for Medicinal Products for Human Use (CHMP). Annex Guideline on Similar Biological Medicinal Products Containing Biotechnology-derived Proteins as Active Substance: Non-clinical and Clinical Issues. Guidance on Similar Medicinal Products Containing Somatropin. London: European Medicines Agency; 2006. Available from: http://www.ema.europa.eu/docs/en_GB/document_library/Scientific_guideline/2009/09/WC500003956.pdf. Accessed December 7, 2010 .
16. Committee for Medicinal Products for Human Use (CHMP). Guideline on Similar Biological Medicinal Products Containing Biotechnologyderived Proteins as Active Substance: Quality Issues. London: European Medicines Agency; 2006. Available from: http://www.ema.europa. eu/docs/en_GB/document_library/Scientific_guideline/2009/09/ WC500003953.pdf. Accessed December 7, 2010.

17. European Medicines Agency [homepage on the Internet]. European Public Assessment Reports. London: European Medicines Agency; 2005-2012. Available from: http://www.ema.europa.eu. Accessed August 11, 2011.

18. Declerck PJ, Darendeliler F, Goth M, et al. Biosimilars: controversies as illustrated by rhGH. Curr Med Res Opin. 2010;26:1219-1229.

19. Committee for Medicinal Products for Human Use (CHMP). Guideline on Immunogenicity Assessment of Biotechnology-Derived Therapeutic Proteins. London: European Medicines Agency; 2007. Available from: http://www.ema.europa.eu/docs/en_GB/document_library/Scientific_ guideline/2009/09/WC500003946.pdf. Accessed August 5, 2011.

20. Grabowski HG, Ridley DB, Schulman KA. Entry and competition in generic biologics. Manage Decis Econ. 2007;28:439-451.

21. Grabowski H, Cockburn I, Long G. The market for follow-on biologics: how will it evolve? Health Aff (Millwood). 2006;25:1291-1301.

22. Liefner M. Biosimilars' price dynamic in Europe. In: Mattison N, Mestre-Ferrandiz J, Towse A, editors. Biosimilars: How Much Entry and Price Competition will Result? London: Office of Health Economics; 2010. Available from: http://www.ohe.org/publications/article/ biosimilars-how-much-entry-and-price-competition-will-result-13.cfm. Accessed October 7, 2011.

23. Viejo Viejo I, Stead D. Tendering of biosimilars in the UK - does launch price actually matter? ISPOR 14th Annual European Congress; November 7, 2011; Madrid.

24. McCamish M, Woollett G. Worldwide experience with biosimilar development. MAbs. 2011;3:209-217.

25. Chu R, Pugatch M. Biogenerics or Biosimilars? Discussing the Present, Considering the Future. Stockholm Network; 2009. Available from: http://www.stockholm-network.org/downloads/publications/ Biosimilars_FINAL.pdf. Accessed October 5, 2011.

26. Malhotra H. Biosimilars and non-innovator biotherapeutics in India: an overview of the current situation. Biologicals. 2011;39(5):321-324.

27. European Generic Medicines Association. Biosimilars Handbook, 2nd ed. Brussels: European Generic Medicines Association; 2011.

28. Drummond M, Sculpher MJ, Torrance GW, O’Brien BJ, Stoddart GL. Methods for the Economic Evaluation of Health Care Programmes. 3rd ed. Oxford: Oxford University Press; 2005.

29. Simoens S, Verbeken G, Huys I. Market access of biosimilars: not only a cost issue. Oncologie. 2011;13:218-221.

30. Simoens S, Huys I. Market entry of biosimilar low molecular weight heparins in Europe: opportunities and challenges. Semin Thromb Hemost. 2012.

31. Simoens S. Biosimilar medicines and cost-effectiveness. Clinicoecon Outcomes Res. 2011;3:29-36.

32. Simoens $\mathrm{S}$. Health economics of market access for biopharmaceuticals and biosimilars. J Med Econ. 2009;12:211-218.

33. Human growth hormone (somatropin) for the treatment of growth failure in children (review) (TA188) [webpage on the Internet]. National Institute for Health and Clinical Excellence; 2010. Available from: http://guidance.nice.org.uk/TA188. Accessed December 8, 2010.

34. Scottish Medicines Consortium. Filgrastim, 30 Million Units $(300$ microgram) $/ 0.5 \mathrm{~mL}$ and 48 MillionUnits (480 microgram) $/ 0.8 \mathrm{~mL}$, Prefilled Syringe Containing Solution for Injection or Infusion (Ratiograstim ${ }^{\circledR}$ ). Scottish Medicines Consortium; 2009. Available from: http://www. scottishmedicines.org.uk/files/filgrastim__Ratiograstim_FINAL_ Oct_2009_Revised_031109.doc_for_website.pdf. Accessed December $8,2010$.

35. Scottish Medicines Consortium [webpage on the Internet]. 46708 epoetin zeta (Retacrit). Scottish Medicines Consortium; 2010. Available from: http://www.scottishmedicines.org.uk/Press_Statements/467_08_ epoetin_zeta_Retacrit_. Accessed December 7, 2010. 
36. Stewart A, Aubrey P, Belsey J. Addressing the health technology assessment of biosimilar pharmaceuticals. Curr Med Res Opin. 2010;26: 2119-2126.

37. Greenland P. Boosting market access and global development for biosimilars. EGA conference under the patronage of the Polish Presidency of the Council of the EU: "Stimulating Industrial Policy to Enhance Internal Market Manufacturing and the Export of European Generic and Biosimilar Medicines"; October 11, 2011; Warsaw, Poland.

38. Hodgson J. WHO guidelines presage US biosimilars legislation? Nat Biotechnol. 2009;27:963-965.

39. Holmes DR Jr, Becker JA, Granger CB, et al. ACCF/AHA 2011 Health Policy Statement on Therapeutic Interchange and Substitution: a report of the American College of Cardiology Foundation Clinical Quality Committee. Circulation. 2011;124:1290-1310.
40. Jelkmann W. Biosimilar epoetins and other "follow-on" biologics: update on the European experiences. Am J Hematol. 2010;85:771-780.

41. European Medicines Agency. Questions and Answers on Biosimilar Medicines (Similar Biological Medicinal Products). London: European Medicines Agency; 2012. Available from: http://www.ema.europa.eu/ docs/en_GB/document_library/Medicine_QA/2009/12/WC500020062. pdf. Accessed November 6, 2012.

42. Moran N. Fractured European market undermines biosimilar launches. Nat Biotechnol. 2008;26:5-6.
Biosimilars

\section{Publish your work in this journal}

Biosimilars is an international, peer-reviewed, open access journal focusing on the manufacture, development and medicinal use of biopharmaceutical compounds considered similar to an innovator agent. Specific topics covered in the journal include: Regulatory issues and pathways; manufacturing processes; chemical composition and

\section{Dovepress}

structure; quality and purity; patent issues; bioequivalence and interchangeability; clinical efficacy data; patient perspectives. The manuscript management system is completely online and includes a very quick and fair peer-review system. Visit http://www.dovepress.com/ testimonials.php to read real quotes from published authors. 